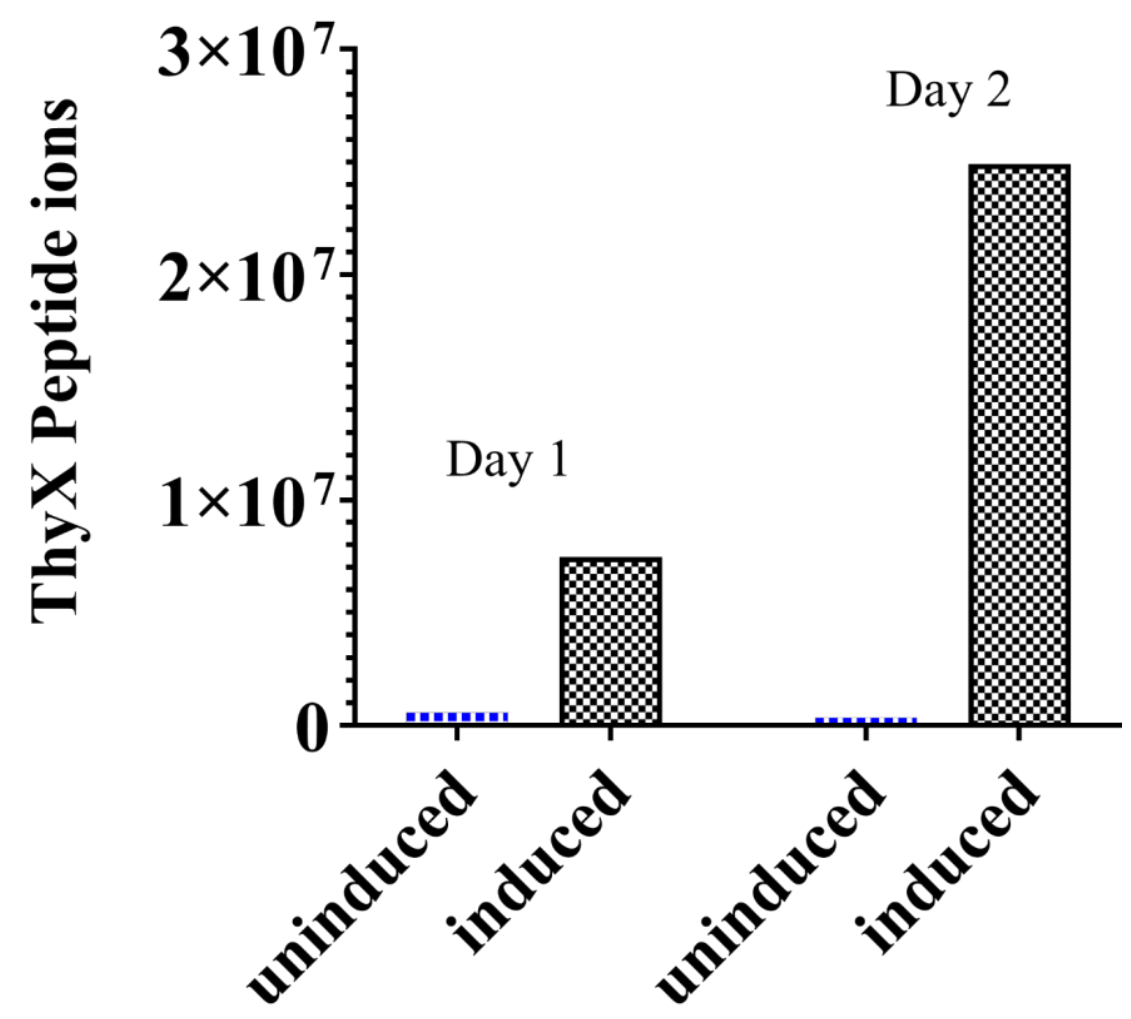

\title{
Induction of gene expression
}

Fig. S3.

Expression of Mtb ThyX gene in Msm using a recombinant plasmid based on the mycobacterial expression vector pLAM. We used a differential proteomics based approach to quantify the extent to which Mtb ThyX accumulates in Msm cells expressing a recombinant version of the gene. The cells were harvested by centrifugation, followed by suspension in $4 \mathrm{ml}$ of Tris (50 $\mathrm{mM}$ ) and then disrupted using a French Press. The lysate was centrifuged followed by dialysis of the supernatant against $50 \mathrm{mM}$ Tris $\mathrm{HCl}$. The dialysate was lyophilised and resuspended in Ammonium bicarbonate $(\mathrm{ABC})(100 \mathrm{mM})$ solution. For protein digestion about $4 \mathrm{mg}$ protein was taken in $100 \mu \mathrm{l}$ of $\mathrm{ABC}$ solution and processed for trypsinization as per standard procedure [23]. The tryptic digests of the extracts were analysed by performing Liquid Chromatography Mass Spectroscopy (LCMS) using a Waters XeVo G2 XS QTof. The analysis was done using Proteomics MSEScan from 0 to 60 minutes. Peptides corresponding to Mtb Thy X were detected using the Progenesis Q1 software provided with the equipment. The results are presented for two experiments performed independent of each other on two different days. 
